\title{
Cadmium Exposure and Renal Effect in Soldering Iron Workers
}

\author{
Tomoyuki Kawada ${ }^{1}$
}

Received: 12 April 2016 / Accepted: 2 May 2016 / Published online: 7 May 2016

(C) Springer Science+Business Media New York 2016

I read with interest the published article in Biological Trace Element Research by Mortada et al. [1]. The authors specified that cadmium $(\mathrm{Cd})$ exposure, monitored in samples of blood and urine, was significantly associated with urinary Nacetyl- $\beta$-D-glucosaminidase (NAG) and beta 2-microglobulin (BMG) in 49 soldering iron workers, aged from 22 to 38 years old. I have some concerns on their study outcome.

The authors enrolled soldering iron workers, and the level of cadmium exposure was obvious by monitoring blood and urine cadmium in their Table 5. I previously reported that renal effect by occupational $\mathrm{Cd}$ exposure with geometric mean value of urinary cadmium around $1 \mu \mathrm{g} / \mathrm{g}$ creatinine, and a significant association with urinary $\mathrm{Cd}$ was observed in urinary NAG [2]. As the significant association between urinary CD and urinary BMG was not consistent, I recommended using urinary NAG as an early indicator of renal effect. Thereafter, I observed the usefulness of urinary NAG for monitoring early renal effect in low-dose $\mathrm{Cd}$ pigment workers [3]. Kim et al. reported that residents with urinary $\mathrm{Cd}$ levels higher than $5 \mu \mathrm{g} / \mathrm{g}$ creatinine showed significant associations with urinary NAG and urinary BMG [4], and urinary BMG would be a good indicator of $\mathrm{Cd}$ exposure as urinary $\mathrm{Cd}$ increases.

Finally, adjustment of smoking habit on the association between $\mathrm{Cd}$ exposure and renal effect is needed [5]. If the

Tomoyuki Kawada

kawada@nms.ac.jp

1 Department of Hygiene and Public Health, Nippon Medical School, 1-1-5 Sendagi, Bunkyo-Ku, Tokyo 113-8602, Japan number of subjects is limited, appropriate adjustment by multivariate analysis cannot be conducted. As the absolute values of correlation coefficient are not so high, further study is required to confirm their study. In addition, indices of $\mathrm{Cd}$ and markers of renal damage are not normal distribution, appropriate transformation is needed. I appreciate their study presenting the appropriate procedure of $\mathrm{Cd}$ measurement, and I pointed out some basic queries on their study.

\section{Compliance with Ethical Standards}

Conflict of Interest The author declares that he has no conflict of interest.

\section{References}

1. Mortada WI, Hassanien MM, Donia AF, Shokeir AA (2015) Application of cloud point extraction for cadmium in biological samples of occupationally exposed workers: relation between cadmium exposure and renal lesion. Biol Trace Elem Res 168:303-310

2. Kawada T, Koyama H, Suzuki S (1989) Cadmium, NAG activity, and beta 2-microglobulin in the urine of cadmium pigment workers. Br J Ind Med 46:52-55

3. Kawada T, Tohyama C, Suzuki S (1990) Significance of the excretion of urinary indicator proteins for a low level of occupational exposure to cadmium. Int Arch Occup Environ Health 62:95-100

4. Kim YD, Yim DH, Eom SY, Moon SI, Park CH, Kim GB, Yu SD, Choi BS, Park JD, Kim H (2015) Temporal changes in urinary levels of cadmium, $N$-acetyl- $\beta$-d-glucosaminidase and $\beta 2$-microglobulin in individuals in a cadmium-contaminated area. Environ Toxicol Pharmacol 39:35-41

5. Koyama H, Satoh H, Suzuki S, Tohyama C (1992) Increased urinary cadmium excretion and its relationship to urinary N-acetyl-beta-Dglucosaminidase activity in smokers. Arch Toxicol 66:598-601 